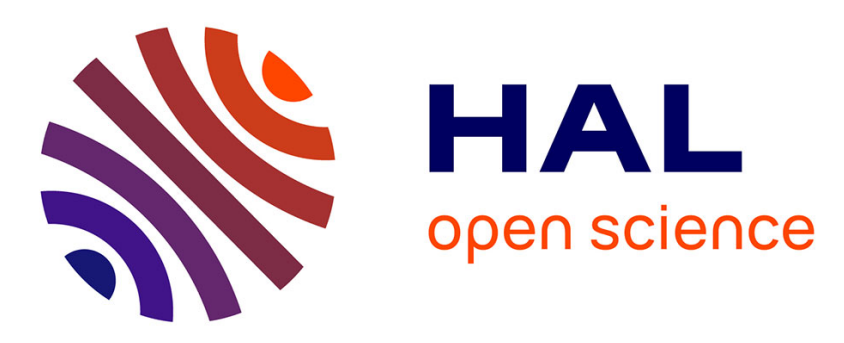

\title{
A new vision of photodarkening in Yb-doped fibers
}

Romain Peretti, Anne-Marie Jurdyc, Cedric Gonnet

\section{To cite this version:}

Romain Peretti, Anne-Marie Jurdyc, Cedric Gonnet. A new vision of photodarkening in Yb-doped fibers. Photonics West: Optical Components and Materials IX, Jan 2012, San Francisco, California, United States. pp.825705, 10.1117/12.914613 . hal-00676689

\section{HAL Id: hal-00676689 \\ https://hal.science/hal-00676689}

Submitted on 6 Mar 2012

HAL is a multi-disciplinary open access archive for the deposit and dissemination of scientific research documents, whether they are published or not. The documents may come from teaching and research institutions in France or abroad, or from public or private research centers.
L'archive ouverte pluridisciplinaire HAL, est destinée au dépôt et à la diffusion de documents scientifiques de niveau recherche, publiés ou non, émanant des établissements d'enseignement et de recherche français ou étrangers, des laboratoires publics ou privés. 


\title{
A NEW VISION OF PHOTODARKENING IN Yb ${ }^{3+}$-DOPED FIBERS
}

\author{
Romain PERETTI $^{1,3}$, Cédric GONNET $^{2}, \underline{\text { Anne-Marie JURDYC }}^{1 *}$ \\ ${ }^{1}$ LPCML- Université de Lyon, Université Lyon 1, CNRS, Villeurbanne F-69622, France \\ ${ }^{2}$ Draka, Data center IV, Route de Nozay, 91460 Marcoussis, France \\ ${ }^{3}$ now at INL-UMR 5270, CNRS, Ecole Centrale de Lyon, F-69134 Ecully Cedex, France \\ *anne-marie.jurdyc@univ-lyon1.fr
}

\begin{abstract}
$\mathrm{Yb}^{3+}$-doped fiber is one of the most promising hosts for high-power fiber lasers [1]. However, in the late 1990s, photodarkening effect, i.e., the creation of color centers induced by light, was observed and reported [2]. Like in other rare-earth-doped materials, a broad visible and near infrared absorption band appears during laser operation, which strongly lowers the laser efficiency. We show how thulium impurities, present at the parts-per-billion weights (ppbw) level in the raw doping material, can induce UV emission, which in turn creates defects responsible for photodarkening in ytterbium-doped continuous-wave fiber lasers [3]. This new vision is not in contradiction with others but it gives for the first time a possible explanation for the creation of UV defects by an infrared beam.
\end{abstract}

Keywords: photodarkening, Yb-doped fiber, Tm upconversion

\section{INTRODUCTION}

Ytterbium-doped fiber lasers (YDFL) are currently the preferred gain medium for high-power fiber lasers because of their high efficiency, broad gain bandwidth, and operational wavelength around $1060 \mathrm{~nm}$ [1]. Unfortunately, this material suffers from photodarkening (PD) effect, i.e., absorption in the visible and near infrared originating from the creation of color centers in the silica network. This problem is typically overcome by using large-mode-area (LMA) fibers [4]. But even with these fibers photo-induced absorption (PIA) has been observed [5]. Solutions to photobleach the fibers are proposed in this paper to repair the fibers, but it will still be interesting to understand the origin of the creation of these defects. In the last few years, different mechanisms have been proposed to explain the formation of color centers, among them charge transfer bands [6-8] and oxygen-deficient centers [10]. Yb-associated oxygen deficiency centers (ODC), with an absorption peak at $220 \mathrm{~nm}$, were proposed as a precursor to photodarkening in Yb-doped aluminosilicate fibers [10]. Non-bridging oxygen holes [9], and even $\mathrm{Yb}^{2+}-\mathrm{Yb}^{3+}$ pairs [11] have also been suggested. But the question remains: how is it possible to create these defects in the visible with an IR pump? We propose here that the presence of thulium ions, even at very low concentration levels, can lead to UV light, which suggests the need to use Tm-free materials.

\section{RESULTS}

Two phospho-aluminosilicate fibers ( $3.3 \mathrm{w} \%$ aluminium and $1 \mathrm{w} \%$ phosphorus) doped with $1.7 \mathrm{wt} . \%$ ytterbium were studied. The usual MCVD technique followed by a soaking method was used to incorporate the ytterbium ions via a high-purity N48 (99.998\%) ytterbium chloride solution into the silica matrix. The first sample is doped only with $\mathrm{Yb}$ and is referred to as the $\mathrm{Yb}$ sample. The second one is co-doped with 0.03 wt.\% thulium (Yb-Tm sample). Despite the

Optical Components and Materials IX, edited by Shibin Jiang, Michel J. F. Digonnet, J. Christopher Dries, Proc. of SPIE Vol. 8257, 825705 - (C) 2012 SPIE · CCC code: 0277-786X/12/\$18 · doi: 10.1117/12.914613 
high purity of the raw doping material (N48), the presence of impurities even in very small quantities (below 340 ppbw) could still be possible. In fact, in the "pure" Yb sample the Tm impurity has been measured at the level of 210 ppbw by induction coupled plasma spectroscopy.

As we can see in Figure 1, thulium emission bands have been identified in our two samples. Four distinct emission bands are observed across the spectral range; each of these bands is normalized to its maximum in the figure. All bands at $300 \mathrm{~nm}, 360 \mathrm{~nm}, 475 \mathrm{~nm}$ and $650 \mathrm{~nm}$ can be attributed to the presence of $\mathrm{Tm}^{3+}$ ions according to the spectroscopy database (see for example $[12,13])$. In the literature these emissions are assigned to the $\left({ }^{1} \mathrm{I}_{6},{ }^{3} \mathrm{P}_{0}\right){ }^{3} \mathrm{H}_{6}$; ${ }^{1} \mathrm{D}_{2}-{ }^{3} \mathrm{H}_{6} ;{ }^{1} \mathrm{G}_{4}-{ }^{3} \mathrm{H}_{6}$ and ${ }^{1} \mathrm{G}_{4}-{ }^{3} \mathrm{~F}_{4}$ transitions, respectively. One emission band (around $520 \mathrm{~nm}$ ) cannot be assigned to $\mathrm{Tm}^{3+}$ emission, but results from a cooperative process involving two $\mathrm{Yb}^{3+}$ ions [14]. While exciting the fiber in the IR we have not observed any emission coming from $\mathrm{Yb}^{2+}$ ions or from defect centers. These emissions have been seen only under $\mathrm{UV}$ excitation for $\mathrm{Yb}^{2+}[6]$ or ODC [15]. Note that we have not observed either any emission around $330 \mathrm{~nm}$ coming from hypothetical clusters of three $\mathrm{Yb}^{3+}$.

It is interesting to note that cooperative emission of pairs of $\mathrm{Yb}^{3+}$ associated to $1.7 \mathrm{wt} . \%$ of ytterbium has the same intensity as the ${ }^{1} \mathrm{G}_{4}-{ }^{3} \mathrm{H}_{6}$ emission of $210 \mathrm{ppbw}$ of $\mathrm{Tm}^{3+}$. This effect has been also observed by Goldner et al. [16]. The cooperative emission efficiency is very low, around $10^{-8} \mathrm{~cm}^{2} / \mathrm{W}$ [17] even if this emission is plainly visible to the naked eyes.
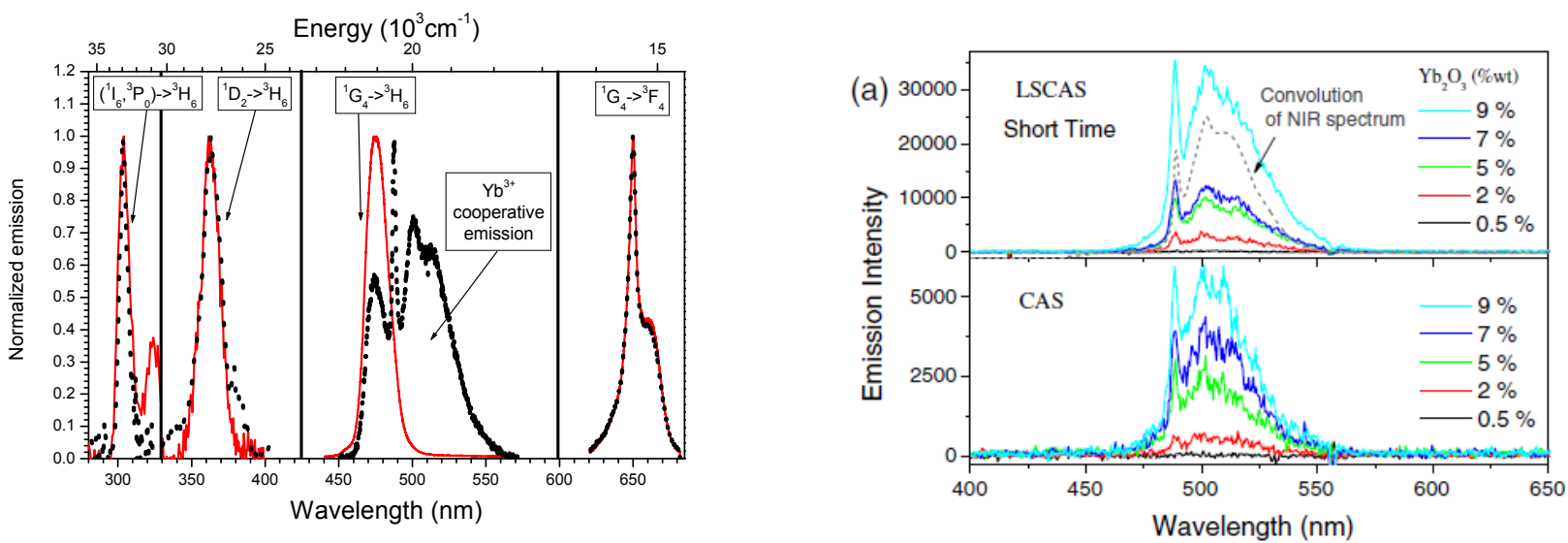

Figure 1: a) UV and visible normalized emissions of the Yb-doped sample (black dotted lines) and Yb-Tmcodoped sample (red solid lines) with 200-mW cw excitation at $976 \mathrm{~nm}$; b) from [13], cooperative luminescence spectrum of the $\mathrm{Yb}$ in two different calcium aluminosilicate glasses.

Despite the high purity of the raw doping material (N48) used to manufacture the $\mathrm{Yb}$ sample, the presence of thulium contamination even in very small quantities $(210 \mathrm{ppbw})$ still produces a significant light emission. The blue emission has also been attributed to thulium by Jetschke et al. [18] and it can be also clearly identified in [19-20]. The emission at $375 \mathrm{~nm}$ was observed in Tm-doped silica fibers by Hanna et al. [21]. But, to our knowledge, this is the first time that a UV emission around $300 \mathrm{~nm}$ is measured in silica glass. Nevertheless, this emission band has already been seen in polycrystalline $\mathrm{AlF}_{3}$ particles doped with $0.2 \% \mathrm{Tm}^{3+}, 10 \% \mathrm{Yb}^{3+}[22]$ and in $\mathrm{Tm}^{3+} / \mathrm{Yb}^{3+}$ codoped $\mathrm{YF}_{3}$ nanocrystals [23]. In a $\mathrm{Tm}^{3+}$-doped ZBLAN fiber El-Agmy [24] obtained a continuous-wave laser of $42 \mu \mathrm{W}$ at $284 \mathrm{~nm}$ pumped with $590 \mathrm{~mW}$ from a Nd:YAG laser operated at $1.064 \mu \mathrm{m}$.

Figure 2 shows a schematic energy level diagram of $\mathrm{Tm}^{3+}$ and $\mathrm{Yb}^{3+}$ ions. Depending on the $\mathrm{Tm}$ concentration, two different mechanisms have been proposed to excite $\mathrm{Tm}^{3+}$ ions up to the ${ }^{1} \mathrm{I}_{6}$ level [22-24]. For high $\mathrm{Tm}$ concentrations a cross relaxation (CR) process can be observed between $\mathrm{Tm}$ ions in addition to $\mathrm{Yb}$ - Tm energy transfer (ET), whereas for low Tm concentrations a 5 steps $\mathrm{Yb}$-Tm ET was suggested [25], leading to the successive population of the ${ }^{3} \mathrm{H}_{5},{ }^{3} \mathrm{~F}_{2}$, ${ }^{1} \mathrm{G}_{4},{ }^{1} \mathrm{D}_{2}$ and finally the ${ }^{3} \mathrm{P}_{0^{-}}{ }^{1} \mathrm{I}_{6}$ energy levels. In addition, it was shown in [24] how increasing the ratio of $\mathrm{Yb}^{3+}$ to $\mathrm{Tm}^{3+}$ 
concentrations leads to an increase in the populations of the ${ }^{1} I_{6}$ and ${ }^{1} D_{2}$ levels, and therefore an enhanced emission in the UV.

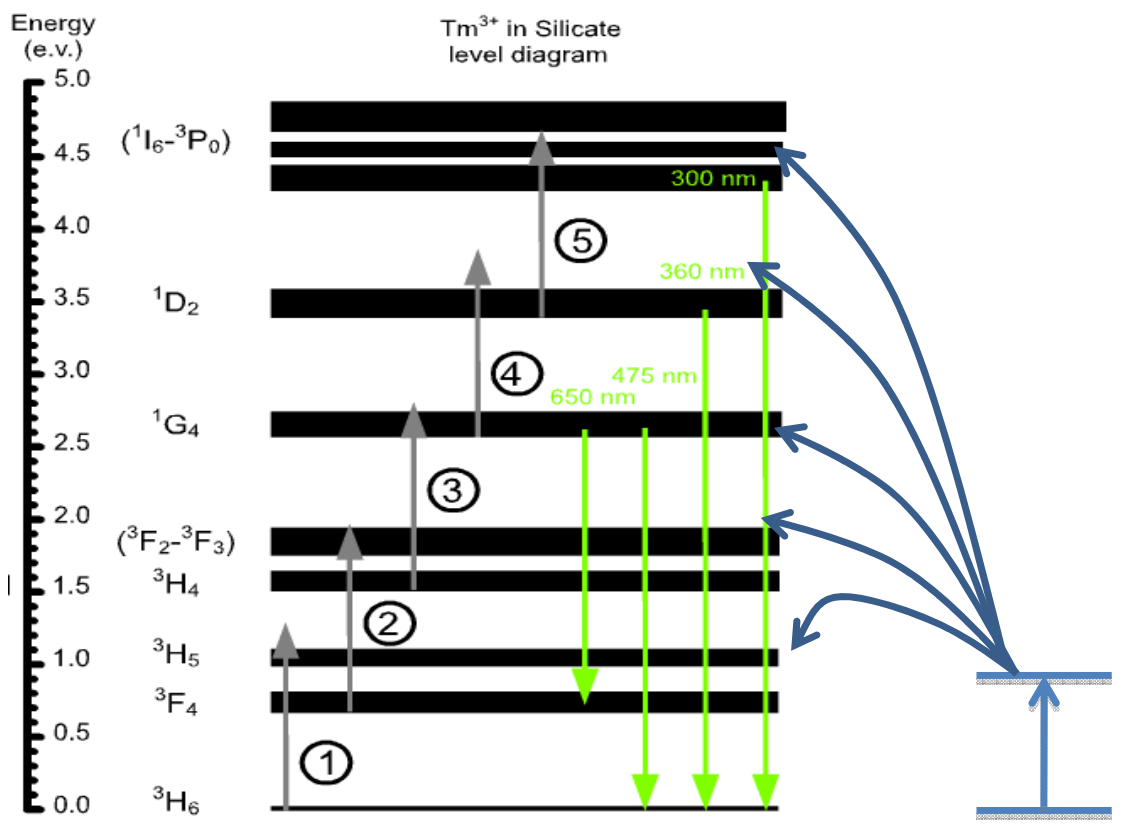

Figure 2: Schematic of the $\mathrm{Tm}^{3+}$ and $\mathrm{Yb}^{3+}$ energy levels with the different emissions observed.

UV photons are thus easily generated in a fiber thanks to $\mathrm{Tm}^{3+}$ ions, even at very low concentration; it is in fact possible to create defects in an optical fiber only with a UV lamp [26]. If the sample is "free" from $\mathrm{Tm}^{3+}$ one has to come up with another process to create UV absorption. In Figure 3, we represent schematically the commonly cited mechanism involving cooperative excitation between three $\mathrm{Yb}^{3+}$ ions (Figure 3a), a mechanism we deem would have an extremely low probability of occurrence, and suggest in Figure $3 \mathrm{~b}$ a possible cooperative sensitization process. The efficiency of this second phenomenon is around 2 orders of magnitude higher than the cooperative emission [17].

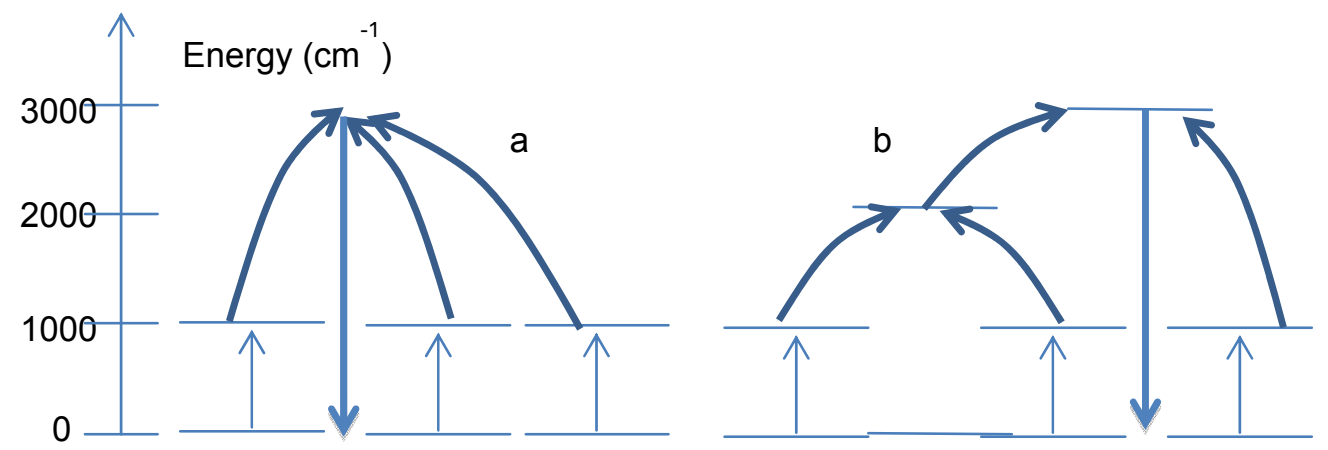

Figure 3: Mechanisms to reach the UV levels in Tm-free samples: a) cooperative emission between three $\mathbf{Y b}^{3+}$ ions, b) and cooperative sensitization.

We have shown [3] that photon-induced absorption (PIA) as a function of time is higher and its establishment faster in the $\mathrm{Yb}-\mathrm{Tm}$ sample than in the $\mathrm{Yb}$ sample. The same result has been observed in figure $3 \mathrm{~b}$ of reference [18]. In that figure, it is difficult to conclude whether there is any difference between the samples containing 0.04 and 0.08 mole ppm of $\mathrm{Tm}_{2} \mathrm{O}_{3}$. But one can clearly see an increase in the PIA between the 0.08 and 7 mole ppm samples. Although there 
is no additional measurement between samples contaminated with 0.04 and 0.08 mole ppm, the authors speculate that the thulium should not have any effect below 1 mole ppm but it can be kept below 0.1 mole ppm anyway.

We have used the classical stretched exponential function below to fit our data [27]:

$$
\alpha(t)=\alpha_{s t}\left[1-\operatorname{cxp}\left(-\left(\frac{t}{\tau}\right)^{\beta}\right)\right]
$$

where $\alpha(t)$ represents the loss induced at a time $t$ after the pump is switched on, $\alpha_{e q}$ is the loss at the final equilibrium state, $\tau$ a time scale, and $\beta$ the stretching parameter, respectively. Note that, as shown in [28], $\beta$ corresponds to the distribution of $\tau$ among the phenomenon (or the phenomena) leading to PD.

We can see Figure 4 the different fits we have done on our data. PIA versus time is fitted with the stretched exponential function with either $\beta$ free or assigning to it a fixed values namely 0.5 or 0.7 for the $\mathrm{Yb}$ fiber and 0.6 and 1 for the $\mathrm{Yb}$-Tm fiber. It can be observed that all the fits are good.
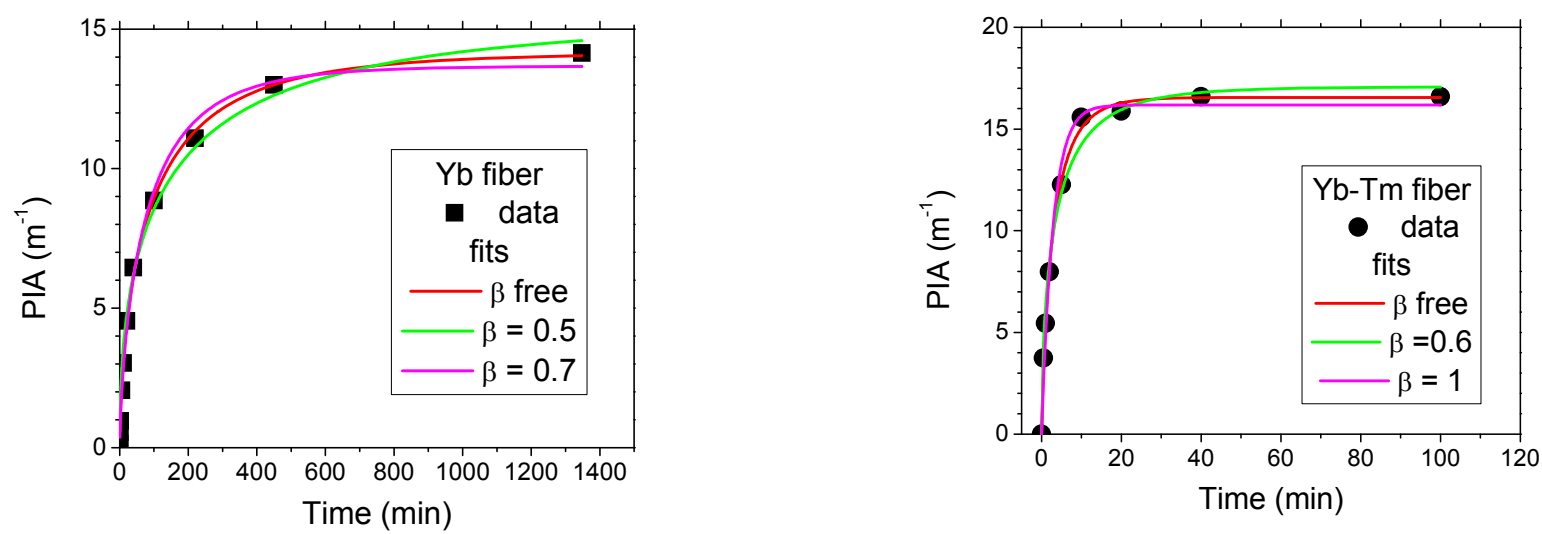

Figure 4: Different fittings of the PIA variation with time for the Yb fiber (left) and the Yb-Tm fiber (right).

Table 1: Fitting parameters for the Yb-sample.

\begin{tabular}{|c|c|c|c|c|c|c|}
\hline & Value & Error & Value & Error & Value & Error \\
\hline$\alpha_{\text {st }}$ & 14.1 & 0.2 & 13.7 & 0.3 & 15.4 & 0.6 \\
\hline$\beta$ & 0.62 & 0.02 & 0.7 & Fixed & 0.5 & fixed \\
\hline$\tau$ & 100 & 8 & 86 & 7 & 152 & 26 \\
\hline
\end{tabular}

Table 2: Fitting parameters for the Yb-Tm sample

\begin{tabular}{|c|c|c|c|c|c|c|}
\hline & Value & Error & Value & Error & Value & Error \\
\hline$\alpha_{\text {st }}$ & 16.5 & 0.2 & 17 & 0.5 & 16 & 0.4 \\
\hline$\beta$ & 0.78 & 0.04 & 0.6 & Fixed & 1 & fixed \\
\hline$\tau$ & 3.3 & 0.2 & 3.8 & 0.5 & 2.9 & 0.3 \\
\hline
\end{tabular}

Although we have made careful measurements to ensure equal and uniform inversion just as in [27], our stretching parameters $\beta$ is not constant. Actually, adding Tm can modify the PD phenomenon not only quantitatively but 
qualitatively (UV emission spectra or dynamics, for example); as a result, the $\tau$ distribution will change and so will $\beta$. This is why we think that it is really difficult to extract comparable parameters for $\alpha_{s t}$ and $\tau$. We can only verify in Table 1 and Table 2 that the $\tau$ factor is much higher in the $\mathrm{Yb}-\mathrm{Tm}$ fiber, confirming that the PIA is faster in the codoped sample.

Another difficulty to interpret the photodarkening origins is that PIA depends on the wavelength. As we can see in Figure 5, the increase in absorption varies with wavelength.

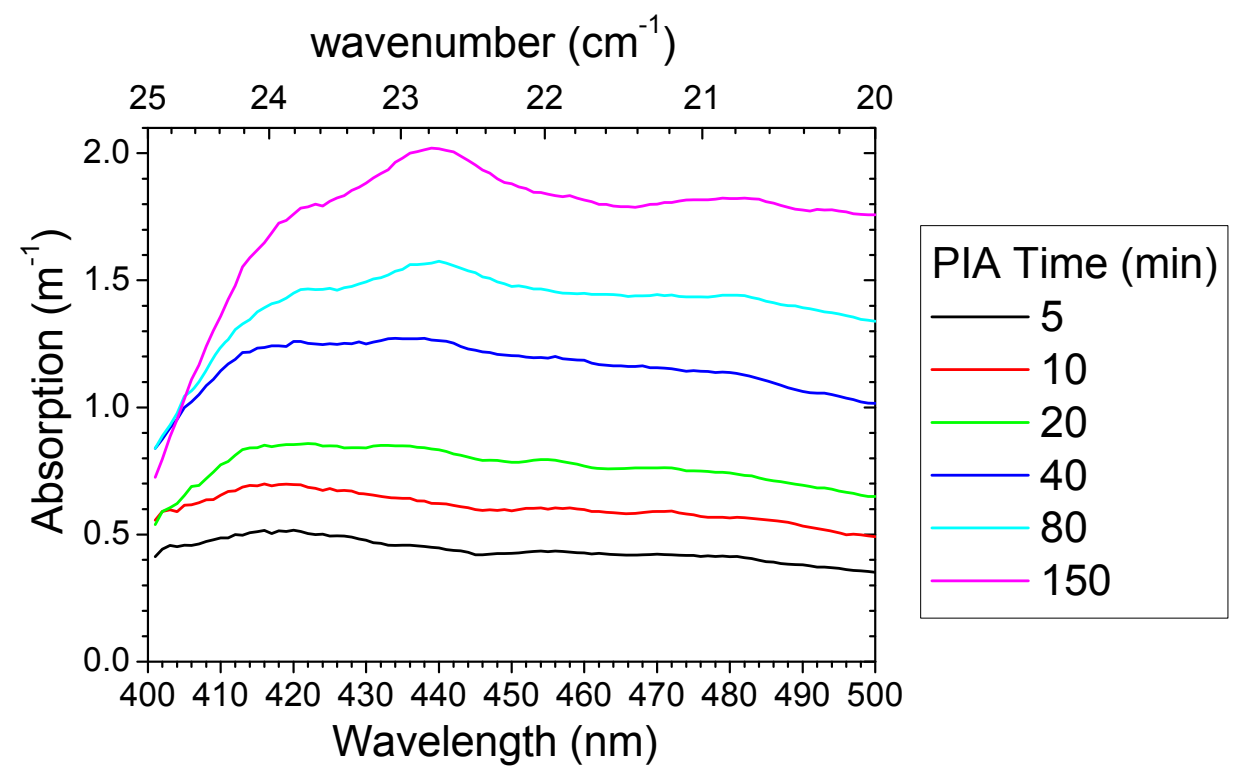

Figure 5: Absorption as a function of wavelength versus time in Yb sample

PIA is usually measured at a single probe wavelength; moving to another wavelength will change the shape of the PIA and its interpretation. In Figure 5 we can clearly see a different dynamic of evolution at $440 \mathrm{~nm}$ compared to 490 $\mathrm{nm}$, showing for example that new defects are growing over time. We did not push this study further, but it is clear that a band appears around $440 \mathrm{~nm}$, which can be attributed to the creation of ODC. Regarding the mechanism we proposed in Figure $3 b$, two $\mathrm{Yb}^{3+}$ can sensitize an ODC in the visible, then a new transfer can help reach UV levels, for example in ODC centers $[10,15]$.

\section{CONCLUSION}

Photodarkening in $\mathrm{Yb}^{3+}$-doped fiber is explained by the creation of defects that absorb visible or UV light. The presence of UV photons is necessary to generate these defects. Mechanisms leading to UV photons emission are not yet fully understood. A cooperative process involving three $\mathrm{Yb}^{3+}$ to reach $\mathrm{UV}$ absorption is highly unlikely because of the very weak efficiency of this process. The presence of $\mathrm{Yb}^{2+}$ ions or silica defects such as ODC could be a part of the explanation, but these hypotheses are not easy to confirm experimentally. A cooperative sensitization of two $\mathrm{Yb}^{3+}$ ions using a real intermediate state in the gap could also be possible. In our samples, we have identified the UV emission of $\mathrm{Tm}^{3+}$ ions traces (210 ppbw). Jetschke et al. showed also the effect of $\mathrm{Tm}^{3+}$ ions on the photodarkening process [18] and tried to define a lower limit to the effect of trace impurities of $\mathrm{Tm}$. They estimated that below 1 mole ppm, corresponding to $\sim 65 \mathrm{ppbw}$, there is no detectable impact of $\mathrm{Tm}^{3+}$. We think that more experiments still have to be carried out to accurately define this limit and clarify the $\mathrm{PD}$ dependence on $\mathrm{Yb}^{3+}$ concentration, on the sample composition and preparation, on the pump and signal wavelength and power, etc. Nevertheless, it is obvious that the presence of thulium helps excite UV absorption bands and accelerates the creation of defects. In a recent article, [29] we have shown how this observed impact of thulium ions is reinforced by published results, and how it can be an explanation for 
discrepancies in literature. Care has to be taken to suppress thulium ions in order to reduce PD in Yb-doped fibers by using 5 or even $6 \mathrm{~N}$ raw materials.

\section{REFERENCES}

[1] D. J. Richardson, J. Nilsson, and W. A. Clarkson, "High power fiber lasers: current status and future perspective," J. Opt. Soc. Am. B 27(11), B63-B92 (2010).

[2] R. Paschotta, Nilsson, J., Barber, P. R., Caplen, J. E., Tropper, A. C., and Hanna, D. C., "Lifetime quenching in Ybdoped fibres," Optics Communications 136(5-6), 375-378 (1997)

[3] R. Peretti, A-M. Jurdyc, B. Jacquier, Cédric Gonnet, Alain Pastouret, Ekaterina Burov, and Olivier Cavani, "How do traces of thulium can explain photodarkening in Yb doped fibers?," OPTICS EXPRESS, 18, 20455 (2010)

[4] C.-H.Liu, Ehlers, B., Doerfel, F., Heinemann, S., Carter, A., Tankala, K., Farroni, J., and Galvanauskas, A. , “,” Electron. Let., 40, 23 (2004).

[5] Manek-Hönninger, I; Boullet, J; Cardinal, T; Guillen, F; Ermeneux, S; Podgorski, M; Bello Doua, R; Salin, F, Photodarkening and photobleaching of an ytterbium-doped silica double-clad LMA fiber, Optics Express, 15, 1606-

[6] M. Engholm, L. Norin, and D. Åberg, "Strong uv absorption and visible luminescence in ytterbium-doped aluminosilicate glass under uv excitation"Opt. Lett., 32, 3352 (2007).

[7] M. Engholm, et al., “,” Proc. of SPIE : Solid State Lasers XVIII: Technology and Devices, 7193, (2009).

[8] J. Kirchhof, et al., "The influence of yb2+ ions on optical properties and power stability of ytterbium-doped laser fibers," Proc. SPIE, edited by S. Jiang, M. J. F. Digonnet, J. W. Glesener, and J. C. Dries, 7598, 75980B (2010).

[9] P. D. Dragic, C. G. Carlson, and A. Croteau, "Characterization of defect luminescence in Yb doped silica fibers: part I NBOHC", Opt. Express, 16, 4688 (2008).

[10] S. Yoo, C. Basu, A. J. Boyland, C. Sones, J. Nilsson, J. K. Sahu, and D. Payne, "Photodarkening in Yb-doped aluminosilicate fibers induced by $488 \mathrm{~nm}$ irradiation," Opt. Lett. 32, 1626 (2007).

[11] A. G. Chávez, A. Kir'yanov, Y. Barmenkov, and N. Il'ichev, "Reversible photo-darkening and resonant photobleaching of Ytterbium-doped silica fiber at in-core 977-nm and 543-nm irradiation" Laser Physics Letters, 4, 734 (2007).

[12] R. Piramidowicz, A. Bok, M. Klimczak, and M. Malinowski, "Uv emission properties of thulium-doped fluorozirconate glasses," J. Lumin., 129, 1874-1877 (2009).

[13] P. Jenouvrier, G. Boccardi, J. Fick, A.-M. Jurdyc, and M. Langlet, "Up-conversion emission in rare earth-doped y2ti2o7 sol-gel thin films," J. Lumin, 113(3-4), 291-300 (2005).

[14] Y. Guyot, A. Steimacher, M. P. Belançon, A. N. Medina, M. L. Baesso, S. M. Lima, L. H. C. Andrade, A. Brenier, AM. Jurdyc, and G Boulon, "Spectroscopic properties, concentration quenching, and laser investigations of Yb3+doped calcium aluminosilicate glasses," J. Opt. Soc. Am. B, 28, 2510 (2011)

[15] C. G. Carlson, K. E. Keister, P. D. Dragic, A. Croteau, and J. G. Eden, Photoexcitation of Yb-doped aluminosilicate fibers at $250 \mathrm{~nm}$ : evidence for excitation transfer from oxygen deficiency centers to Yb3+, JOSA B, 27, 2087-2094 (2010)

[16] P. Goldner, B. Schaudel, and M. Prassas, Dependence of cooperative luminescence intensity on Yb3+ spatial distribution in crystals and glasses, Phys. Rev. B 65, 054103 (2002).

[17] François Auzel, "Upconversion and Anti-Stokes Processes with f and d Ions", Solids Chem. Rev., 104, 139-174 (2004)

[18] Sylvia Jetschke, Martin Leich, Sonja Unger, Anka Schwuchow, and Johannes Kirchhof, "Influence of Tm- or Ercodoping on the photodarkening kinetics in Yb fibers," OPTICS EXPRESS, 19, 14473 (2011)

[19] A. Kir'yanov, "Electron-Irradiation and Photo-Excitation Darkening and Bleaching of Yb Doped Silica Fibers: Comparison," Optics and Photonics Journal, 4, 1 (2011)

[20] A V. Kir'yanov, Yuri O. Barmenkov, and Itzel Lucio Martinez, Andrey S. Kurkov and Evgenii M. Dianov, "Cooperative luminescence and absorption in Ytterbium-doped silica fiber and the fiber nonlinear transmission coefficient at $\lambda=980 \mathrm{~nm}$ with a regard to the Ytterbium ion-pairs' effect," Optics Express, 14, Iss. 9, 3981-3992 (2006)

[21] D.C. HANNA, R.M. PERCIVAL, I.R. PERRY, R.G. SMART, J.E. TOWNSEND and A.C. TROPPER, "Frequency upconversion in Tm-and Yb: Tm-doped silica fibers," Opt. Com., 78, 187 (1990). 
[22] Guanshi Qin, Weiping Qin, Changfeng Wu, Shihua Huang, Dan Zhao, Jisen Zhang, Shaozhe Lu, "Infrared-toultraviolet up-conversion luminescence from AlF3: $0.2 \% \mathrm{Tm} 3+, 10 \% \mathrm{Yb} 3+$ particles prepared by pulsed laser ablation," Solid State Communications, 125, 377-379 (2003)

[23] Chunyan Cao, Weiping Qin, Jisen Zhang, Yan Wang, Peifen Zhu, Guofeng Wang, Guodong Wei, Lili Wang, Longzhen Jin, "Enhanced ultraviolet up-conversion emissions of Tm3+/Yb3+ codoped YF3 nanocrystals, "Journal of Fluorine Chemistry, 129, 204-209 (2008)

[24] R. M. El-Agmy, "Upconversion CW Laser at $284 \mathrm{~nm}$ in a Nd:YAG-Pumped Double-Cladding Thulium-Doped ZBLAN Fiber Laser," Laser Physics, 18, 803-806 (2008).

[25] R. J. Thrash and L. F. Johnson, "Upconversion laser emission from Yb3+-sensitized Tm3+ in BaY2F8," JOSA B, $11,881-885$ (1994)

[26] Albert Canagasabey and John Canning, "Uv lamp hypersensitisation of hydrogen-loaded optical fibres." Opt. Express, 11,1585-1589 (2003).

[27]: Stefano Taccheo, Hrvoje Gebavi, Achille Monteville, Olivier Le Goffic, David Landais, David Mechin, Denis Tregoat, Benoit Cadier, Thierry Robin, Daniel Milanese, and Tim Durrant, "Concentration dependence and selfsimilarity of photodarkening losses induced in Yb-doped fibers by comparable excitation", Optics Express, 19, 19340-19345 (2011)

[28] Lindsey, C. P. \& Patterson, G. D., "Detailed comparison of the Williams--Watts and Cole--Davidson functions," The Journal of Chemical Physics, 73, 3348-3357 (1980)

[29] R. Peretti, C. Gonnet, and AM Jurdyc, "Revisiting Literature Observations Regarding Tm-Induced Photodarkening in Yb3+-doped Fibre," submitted (2012). 